\title{
Vaginal Escherichia coli share common virulence factor profiles, serotypes and phylogeny with other extraintestinal $E$. coli
}

\author{
Mana Obata-Yasuoka, ${ }^{1,2}$ William Ba-Thein, ${ }^{2}$ Teizo Tsukamoto, ${ }^{3}$ \\ Hiroyuki Yoshikawa' ${ }^{1}$ and Hideo Hayashi ${ }^{2}$
}
1,2 Department of Obstetrics and Gynaecology, Institute of Clinical Medicine ${ }^{1}$ and Department of Infection Biology, Institute of Basic Medical Sciences 2 University of Tsukuba, Tsukuba, 305-8575, Japan
3 Osaka Prefectural Institute of Public Health, OSaka, 537-0025, Japan

\author{
Author for correspondence: William Ba-Thein. Tel: +8129853 3354. Fax: +81298533354. \\ e-mail: bathein@md.tsukuba.ac.jp
}

\begin{abstract}
Characteristics of Escherichia coli residing in the vagina and their role in extraintestinal infections are largely unknown. In this study, 88 vaginal $E$. coli (VEC) isolates from Japanese women were characterized by extraintestinal virulence factor (VF) profiling, $\mathrm{O}: \mathrm{H}$ serotyping and phylogenetic analysis. The prevalence of papC, hlyA, cnfl, PAl, ibeA and $\mathrm{K} 1$ antigen among the VEC strains were 45, 22, 19, 78, 32 and $44 \%$, respectively. Phylogenetic analysis identified 76,16 and $8 \%$ of the VEC strains in groups B2, D and A, respectively. The VEC strains were distributed into 31 serotypes, including 8 common serotypes (01:K1:H1, 01:K1:H7, 02:K1:H7, 04:H5, 06:H1, 018ac:K1:H7, 025:H1 and 075: HNM) that were identified in three or more isolates. Comparative analysis with 61 stool isolates from healthy Japanese men and women, and with data from previous studies, revealed that, although some geographical specificities do exist, the VEC strains shared common VF profiles, $0: K: H$ serotypes and phylogeny with uropathogenic $E$. coli and $E$. coli of neonatal septicaemia and meningitis. This study provides additional evidence for a link among extraintestinal $E$. coli, supporting the concept that the VEC are a reservoir along the 'faecal-vaginal-urinary/neonatal' course of transmission in the extraintestinal $E$. coli infections.
\end{abstract}

Keywords: vagina, Escherichia coli, extraintestinal virulence factors, phylogenetic grouping, $\mathrm{O}: \mathrm{K}: \mathrm{H}$ antigens

\section{INTRODUCTION}

The vaginal microflora is normally made up of 5-15 different bacterial species, including aerobes and anaerobes, and has the potential to inflict different clinical syndromes (e.g. bacterial vaginosis) and diseases (e.g. pelvic inflammatory disease). Gram-negative facultative anaerobic Escherichia coli is one of the common organisms in the microflora of pregnant as well as nonpregnant women. E. coli have been reportedly identified in $9-28 \%$ of non-pregnant women (Bartlett et al., 1977; Chow et al., 1986; Tashjian et al., 1976) and 24-31\% of pregnant women (Hillier et al., 1993; Tashjian et al., 1976).

Vaginal colonization with E. coli is associated with

Abbreviations: CSF, cerebrospinal fluid; HNM, H non-motile; MLEE, multilocus enzyme electrophoresis; NMEC, neonatal meningitis E. coli; PAI, pathogenicity-associated island marker; UPEC, uropathogenic $E$. coli; VEC, vaginal E. coli; VF, virulence factor. various genitourinary, obstetric and neonatal complications, such as the severe form of pelvic inflammatory disease (Heinonen \& Miettinen, 1994; Larsen \& Galask, 1980), urinary tract infections (O'Grady et al., 1970; Stamey \& Sexton, 1975), very-low-birth-weight infants (Krohn et al., 1997) and early-onset neonatal septicaemia and meningitis (Sarff et al., 1975; Schiffer et al., 1976). Vaginal E. coli has also been reported to be sexually transmissible to a male partner (Hebelka et al., 1993).

The E. coli implicated in various human infections can be broadly classified as intestinal and extraintestinal. Among the extraintestinal E. coli, uropathogenic E. coli (UPEC) and neonatal meningitis E. coli (NMEC) have been characterized in some detail by diverse approaches including phylogenetic analysis, serotyping and molecular typing such as virulence factor (VF) profiling, multilocus enzyme electrophoresis (MLEE), outer-membrane protein profiling and plasmid profiling. Vaginacolonizing E. coli, however, remains largely uncharac- 
terized with regard to its genotypes, serotypes, clonality and phylogenetic linkage with other E. coli.

In this paper we report on the characteristics of E. coli isolates from vaginal swab samples of both pregnant and non-pregnant women as determined by extraintestinal E. coli VF profiling, PCR-based phylogenetic grouping and $\mathrm{O}: \mathrm{H}$ serotyping. We also report on the results of comparative analyses with $E$. coli isolates from normal stool samples and with previous data from stool, urine, blood and cerebrospinal fluid (CSF) isolates (Bingen et al., 1997, 1998; Duriez et al., 2001; Johnson \& Stell, 2000; Johnson et al., 2002; Miyazaki et al., 2002; Sarff et al., 1975; Siitonen, 1992; Tsukamoto, 1997; Yamamoto et al., 1995b).

\section{METHODS}

Study populations. A total of 2575 vaginal swabs (one swab per patient) were collected from patients who visited the Obstetrics and Gynaecology Department in the Mito Saiseikai General Hospital, Ibaraki Prefecture, East Japan between May 1999 and February 2001. Normal stool samples from 106 healthy adult men and women working at a food court in the Tokyo University Hospital, Tokyo, East Japan were kindly provided by Dr Shigemi Hitomi (Department of Infectious Diseases, Institute of Clinical Medicine, University of Tsukuba, Japan).

For comparative analyses with respect to the characteristics of VEC, previously published data on the following were included: (i) VF profiles of $2245 \mathrm{E}$. coli strains of various sources from East Japan (Ibaraki), West Japan (Kyoto, Osaka, Shiga) and other countries, including strains isolated from adult stool $[n=80$ (Yamamoto et al., 1995a), $n=287$ (Siitonen, 1992)], neonatal stool $[n=1169$ (Sarff et al., 1975)], neonatal CSF (bacterial meningitis) [ $n=67$ (Bingen et al., 1997), $n=70$ (Johnson et al., 2002)], neonatal blood (septicaemia) $[n=47$ (Bingen et al., 1997)], adult urine (acute simple cystitis) $[n=194$ (Yamamoto et al., 1995b), $n=256$ (Miyazaki et al., 2002)] and adult blood (urosepsis) $[n=75$ (Johnson \& Stell, 2000)]; (ii) phylogenetic analysis of $307 \mathrm{E}$. coli strains, including strains from normal stool $[n=168$ (Duriez et al., 2001)], neonatal CSF (bacterial meningitis) $[n=69$ (Bingen $e t$ al., 1998), $n=70$ (Johnson et al., 2002)]; (iii) profiles of $\mathrm{O}: \mathrm{H}$ serotypes and $\mathrm{K} 1$ antigen of 320 extraintestinal E. coli strains from neonatal CSF (bacterial meningitis) $(n=52)$, neonatal blood (septicaemia) $(n=74)$ and adult urine (acute simple cystitis) ( $n=194)$ from our previous study (Tsukamoto, 1997).

Sample collection and processing. After obtaining approval from the Ethical Committees of the hospitals concerned and informed consent from the patients, we collected clinical samples. The vaginal swabs were taken from the posterior vaginal fornix by experienced interns and were immediately streaked onto Trypticase soy/5\% sheep blood agar and Drigalsky agar for aerobic cultures. The same swabs were used for microbial identification by Gram staining. Isolates that had been preliminarily identified as E. coli by colony morphology and Gram-stain reactions were confirmed using an API 20E (bioMérieux) kit. The normal stool E. coli strains isolated from Drigalsky agar were also confirmed using an API 20E (bioMérieux) kit. Boiled lysates from at least two batches of overnight-grown bacterial cultures were used as PCR templates for the determination of VFs and phylogenetic groups.

VF profiling. The prevalence of extraintestinal VFs among $E$. coli isolates was examined by a multiplex PCR-based screen- ing method that uses the primer pairs described elsewhere: papC (pilus associated with pyelonephritis) [pap1/2: gacggctgtactgcagggtgtggcg/atatcctttctgcagggatgcaata (Le Bouguenec et al., 1992)]; sfaDE (S fimbriae) [sfa1/2: ctccggagaactgggtgcatcttac/cggaggagtaattacaaacctggca (Johnson \& Brown, 1996); afa/draBC (afimbrial adhesins) [afa1/2: gctgggcagcaaactgataactctc/catcaagctgtttgttcgtccgccg (Le Bouguenec et al., 1992)]; iucD (aerobactin synthesis) [aer1/2: taccggattgtcatatgcagaccgt/aatatcttcctccagtccggagaag (Yamamoto et al., 1995a)]; cnf1 (cytotoxic necrotizing factor) [cnf1/2: aagatggagtttcctatgcaggag/cattcagagtcctgccctcattatt (Yamamoto et al., 1995a); hly A (haemolysin) [hly1/2: aacaaggataagcactgttctggct/accatataagcggtcattccegtca (Yamamoto et al., 1995a); PAI (pathogenicityassociated island marker) [RPAi f/r: ggacatcctgttacagcgcgca/tcgccaccaatcacagccgaac (Johnson \& Stell, 2000)]; fimH (mannose-specific adhesin subunit of type 1 fimbriae) [fimH $\mathrm{f} / \mathrm{r}$ : tgcagaacggataagccgtgg/gcagtcacctgcctccggta (Johnson $\&$ Stell, 2000)]; and ibe A (invasion brain endothelium) [ibe10 $\mathrm{f} / \mathrm{r}$ : aggcaggtgtgcgccgcgtac (Huang et al., 1995) and tggtgctccggcaaaccatgc (Johnson \& Stell, 2000)].

A PCR mixture $(50 \mu \mathrm{l})$ containing $5 \mu \mathrm{l}$ bacterial lysate, $62 \cdot 5 \mu \mathrm{M}$ dNTPs, $5 \mu \mathrm{l} 10 \times$ PCR buffer $(100 \mathrm{mM}$ Tris/HCl, pH $8 \cdot 8$, $500 \mathrm{mM} \mathrm{KCl}, 15 \mathrm{mM} \mathrm{MgCl}_{2}, 1 \%$ Triton X-100), Ex Taq DNA polymerase $\left(0.03 \mathrm{U} \mathrm{\mu l}^{-1}\right)$ (TaKaRa Shuzo) and primer set $\mathrm{A}$ (20 pmol each of pap1/2, sfa1/2, afa $1 / 2$, aer $1 / 2$ and $\mathrm{cnf} 1 / 2$ primers; $30 \mathrm{pmol}$ each of hly $1 / 2$ primers) or primer set $\mathrm{B}$ (10 pmol each of RPAi $\mathrm{f} / \mathrm{r}$, fimH f/r and ibe10 $\mathrm{f} / \mathrm{r}$ primers) was amplified in a thermal cycler (PTC-100; MJ Research) for 30 cycles with a profile of $94^{\circ} \mathrm{C}$ for $1 \mathrm{~min}, 63^{\circ} \mathrm{C}$ for $30 \mathrm{~s}$ and $72{ }^{\circ} \mathrm{C}$ for $3 \mathrm{~min}$, followed by a final extension at $72{ }^{\circ} \mathrm{C}$ for $3 \mathrm{~min}$. Amplified products were separated in $2 \%$ agarose gels, and ethidium bromide-stained gels were visualized with an ultraviolet transilluminator for photographic imaging.

Three methods were used for K1 antigen determination: (i) PCR-based detection of neuS (K1-specific gene) (Tsukamoto, 1997), (ii) antiserum and (iii) bacteriophage-based detection using five K1-specific bacteriophages (Gross et al., 1977). Five bacteriophages specific to the K1 polysaccharide antigen of $E$. coli were kindly supplied by Dr B. Rowe (Central Public Health Laboratory, London, UK) (Gross et al., 1977).

Phylogenetic analysis. Phylogenetic classification of E. coli isolates was determined using triplex PCR-based phylotyping described by Clermont et al. (2000), which is a simple method comparable to MLEE-based typing. Briefly, genomic DNA of bacterial strains was amplified by triplex PCR using primers targeted to three markers, chuA, yjaA and TspE4.C2. The phylogenetic grouping was made on the basis of the presence of specific PCR-amplified fragments as follows: group B2 $($ chu $A+, y j a A+$, TspE.C2 \pm$)$, group D $(\operatorname{chu} A+, y j a A-$,

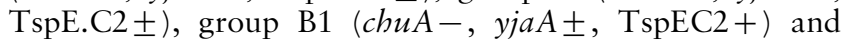
group A (chuA-, yjaA \pm , TspE.C2-).

$\mathbf{O}: \mathbf{H}$ serotyping. The E. coli isolates were serotyped in the Osaka Prefectural Institute of Public Health, Japan, following the method described by Orskov \& Orskov (1975). The Oantigen confirmation for some questionable isolates was performed by the Statens Serum Institute, Denmark. PCRbased H7 typing (Tsukamoto \& Kanki, 1999) was used to assign $\mathrm{H} 7$ to some non-motile (HNM) strains.

Statistical analysis. Significance of differences between the variables was tested with the $\chi^{2}$ test and the Fisher's exact test.

\section{RESULTS}

Eighty-eight VEC isolates from 2575 vaginal swabs were grouped into four subsets according to the clinical background of patients (Table 1) and examined for 
Table 1. Clinical backgrounds of patients in this study

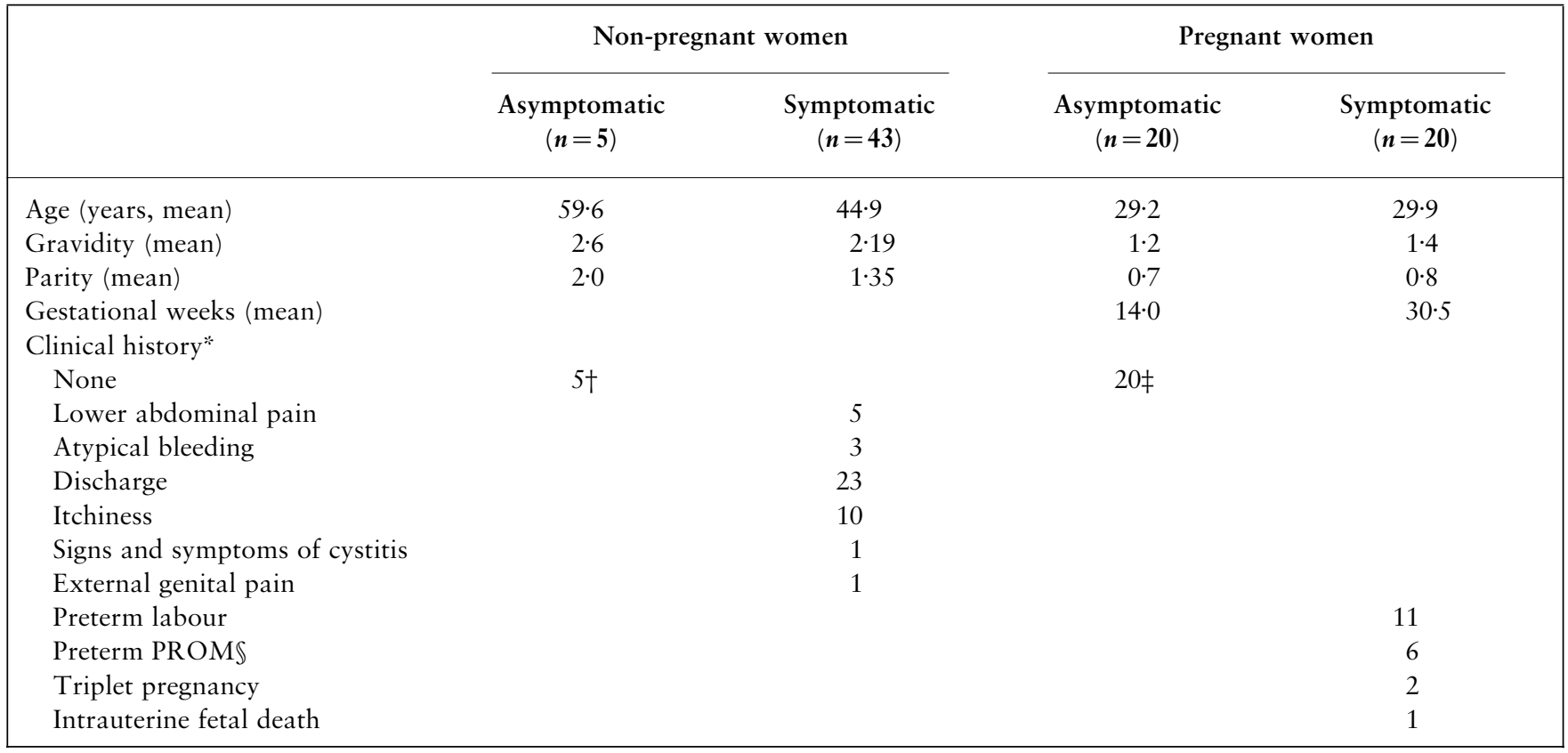

* Only chief complaints are listed.

†Patients visited for screening of cancer and sexually transmitted diseases.

$\ddagger$ Patients visited for prenatal care.

\PROM, premature rupture of membranes.

Table 2. Prevalence of virulence factors among vaginal $E$. coli isolates

Data are shown as no. $(\%)$.

\begin{tabular}{|c|c|c|c|c|c|}
\hline \multirow[t]{2}{*}{ Virulence factor } & \multicolumn{2}{|c|}{ Non-pregnant women } & \multicolumn{2}{|c|}{ Pregnant women } & \multirow{2}{*}{$\begin{array}{c}\text { Total } \\
(n=88)\end{array}$} \\
\hline & $\begin{array}{l}\text { Asymptomatic } \\
\quad(n=5)\end{array}$ & $\begin{array}{l}\text { Symptomatic } \\
\qquad(n=43)\end{array}$ & $\begin{array}{l}\text { Asymptomatic } \\
\quad(n=20)\end{array}$ & $\begin{array}{l}\text { Symptomatic } \\
\quad(n=20)\end{array}$ & \\
\hline \multicolumn{6}{|l|}{ Adhesins } \\
\hline papC & $3(60)$ & $20(47)$ & $7(35)$ & $10(50)$ & $40(45)$ \\
\hline$s f a D E$ & $1(20)$ & $8(19)$ & $3(15)$ & $6(30)$ & $18(20)$ \\
\hline$a f a / d r a B C$ & 0 & $3(7)$ & $1(5)$ & $1(5)$ & $5(6)$ \\
\hline $\mathrm{fimH}$ & $5(100)$ & $43(100)$ & $20(100)$ & $20(100)$ & $88(100)$ \\
\hline \multicolumn{6}{|l|}{ Toxins } \\
\hline blyA & $1(20)$ & $10(23)$ & $2(10)$ & $6(30)$ & $19(22)$ \\
\hline cnf1 & $1(20)$ & $8(19)$ & $2(10)$ & $6(30)$ & 17 (19) \\
\hline \multicolumn{6}{|l|}{ Siderophores } \\
\hline$i u c D$ & $3(60)$ & $16(37)$ & $4(20)$ & $8(40)$ & $31(35)$ \\
\hline \multicolumn{6}{|l|}{ Invasin } \\
\hline ibeA & $1(20)$ & $15(35)$ & $7(35)$ & $5(25)$ & $28(32)$ \\
\hline PAI* & $4(80)$ & $34(79)$ & $17(85)$ & $14(70)$ & $69(78)$ \\
\hline K1 & $2(40)$ & $21(49)$ & $11(55)$ & $5(25)$ & $39(44)$ \\
\hline
\end{tabular}

*PAI, Escherichia coli CFT073 antiterminator homologue and MalX homologue genes in pathogenicity-associated island.

extraintestinal VF profiles, phylogenetic groups and $\mathrm{O}: \mathrm{H}$ serotypes. Sixty-one additional E. coli isolates from the stool samples of 106 healthy people were also included for extraintestinal VF profiling and phylogenetic analysis. The VF profiles of 2245 E. coli strains, together with the phylogenetic grouping of $307 \mathrm{E}$. coli 
Table 3. Prevalence of virulence factors among $E$. coli from various sources

Data are shown as no. $(\%)$.

\begin{tabular}{|c|c|c|c|c|c|c|c|c|c|}
\hline \multirow{2}{*}{$\begin{array}{l}\text { Virulence } \\
\text { factor }\end{array}$} & \multicolumn{2}{|c|}{ Present study } & \multicolumn{7}{|c|}{ Previous studies } \\
\hline & $\begin{array}{l}\text { Vagina* } \\
(n=88)\end{array}$ & $\begin{array}{l}\text { Stool } \dagger \\
(n=61)\end{array}$ & $\begin{array}{l}\text { Stool } \neq \\
(n=80)\end{array}$ & $\begin{array}{c}\text { Urine } \neq \\
(n=194)\end{array}$ & $\begin{array}{c}\text { Urine } \mathbb{S} \\
(n=256)\end{array}$ & $\begin{array}{l}\text { Blood } \| \\
(n=75)\end{array}$ & $\begin{array}{l}\text { Bloods } \\
(n=47)\end{array}$ & $\begin{array}{c}\text { CSF9 } \\
(n=67)\end{array}$ & $\begin{array}{c}\text { CSF\# } \\
(\boldsymbol{n}=\mathbf{7 0})\end{array}$ \\
\hline \multicolumn{10}{|l|}{ Adhesins } \\
\hline sfaDE & $18(20)$ & $7(11)$ & $11(14)$ & $71(37)$ & $44(17)$ & $19(25)$ & $14(30)$ & $29(44)$ & $43(61)$ \\
\hline$a f a / d r a B C$ & $5(6)$ & $4(7)$ & $0(0)$ & $17(9)$ & $13(5)$ & $7(9)$ & $3(6)$ & $2(3)$ & $18(26)$ \\
\hline $\mathrm{fimH}$ & $88(100)$ & $60(98)$ & & & & $75(100)$ & & & \\
\hline \multicolumn{10}{|l|}{ Toxins } \\
\hline bly $A$ & $19(22)$ & $3(5)$ & $14(18)$ & $80(41)$ & $48(19)$ & $31(41)$ & & & $6(9)$ \\
\hline cnf1 & $17(19)$ & $4(7)$ & $10(13)$ & $61(31)$ & $44(17)$ & $12(16)$ & & & $6(9)$ \\
\hline \multicolumn{9}{|l|}{ Siderophore } & \\
\hline \multicolumn{9}{|l|}{ Invasin } & $23(33)$ \\
\hline PAI** & $69(78)$ & $28(46)$ & & & & $53(71)$ & & & $55(79)$ \\
\hline \multirow[t]{2}{*}{ K1 } & $39(44)$ & $13(21)$ & & $93(48)$ & & & & & \\
\hline & & & & & & & $33(70)$ & $55(83)$ & $57(81)$ \\
\hline
\end{tabular}

*Isolates from East Japan (Ibaraki).

† Isolates from East Japan (Tokyo).

‡ Strains from West Japan (Kyoto, Osaka, Shiga), as detected by K1 antigen-specific phages and probe hybridization for other virulence factors (Yamamoto et al., 1995b; Tsukamoto et al., 1997).

\Strains from East Japan (Ibaraki), as detected by PCR (Miyazaki et al., 2002).

$\|$ As detected by PCR (Johnson \& Stell, 2000).

I Strains from neonates, as detected by antisera for K1 antigen and PCR for other virulence factors (Bingen et al., 1997).

\# Strains from neonates, as detected by probe hybridization and PCR (Johnson et al., 2002).

*PAI, Escherichia coli CFT073 antiterminator homologue and MalX homologue genes in pathogenicity-associated island.

strains and serotype data of 320 extraintestinal E. coli strains were used for comparison with that of the VEC isolates.

\section{VF profile}

The prevalence of VFs among the VEC isolates of four clinical subsets is shown in Table 2. There were no significant differences between the non-pregnant women and the pregnant women or between the asymptomatic women and the symptomatic women.

Table 3 shows the comparison of the prevalence of VFs among the E. coli isolates from the present study and previous studies. The prevalence of papC $(45 \%)$, bly A $(22 \%)$, cnf1 $(19 \%)$ and PAI $(78 \%)$ in the VEC isolates was significantly higher than that in the normal stool $E$. coli isolates of this study $(P<0 \cdot 05)$. The prevalence of papC, sfaDE, afa/draBC, hlyA, cnfland iucD of our VEC isolates in Ibaraki prefecture were very similar to those of E. coli strains from cystitis in the same prefecture (Miyazaki et al., 2002), whereas, compared with those in E. coli isolates of cystitis in West Japan and of urosepsis origins, the prevalence of $p a p C, b l y A$ and cnf1 in the VEC isolates appeared lower $(P<0 \cdot 05)$. The prevalence of $i b e A$ in the VEC isolates $(32 \%)$ matched that in the NMEC strains (Table 3) (Bingen et al., 1997; Johnson et al., 2002) and was significantly higher than that in the uroseptic strains $(5 \%)$ (Table 3) (Johnson \& Stell, 2000) $(P<0 \cdot 0001)$.

The prevalence of K1 in the VEC isolates $(44 \%)$ was significantly higher than that in the normal stool E. coli isolates $(21 \%)$ of this study (Table 3$)(P<0 \cdot 005)$ and that in the normal stool E. coli strains from adults $(30 \%)$ and neonates $(19 \%)$ of previous studies (Sarff et al., 1975; Siitonen, 1992) $(P<0.05)$, but was similar to that in the UPEC strains (48\%) (Table 3) (Tsukamoto, 1997; Yamamoto et al., 1995b). About 92\% (48/52) of NMEC strains and $61 \%(45 / 74)$ of neonatal septicaemia E. coli strains were $\mathrm{K} 1$ positive in our previous study (supplementary data available at http://mic. sgmjournals.org. See also Tsukamoto, 1997). The mean prevalence of K1 among the NMEC strains $(48+55+$ $57 / 52+67+70 ; 85 \%$ ) (Bingen et al., 1997; Johnson et al., 2002; Tsukamoto, 1997) was significantly higher than that among the neonatal septicaemia strains $(45+33 / 74+47 ; 64 \%)$ (Bingen et al., 1997; 
Table 4. Distribution of phylogenetic groups among vaginal $E$. coli isolates

Data are shown as no. (\%).

\begin{tabular}{|c|c|c|c|c|c|}
\hline \multirow{2}{*}{$\begin{array}{l}\text { Phylogenetic } \\
\text { group }\end{array}$} & \multicolumn{2}{|c|}{ Non-pregnant women } & \multicolumn{2}{|c|}{ Pregnant women } & \multirow{2}{*}{$\begin{array}{c}\text { Total } \\
(n=88)\end{array}$} \\
\hline & $\begin{array}{l}\text { Asymptomatic } \\
\qquad(n=5)\end{array}$ & $\begin{array}{l}\text { Symptomatic } \\
\quad(n=43)\end{array}$ & $\begin{array}{l}\text { Asymptomatic } \\
\quad(n=20)\end{array}$ & $\begin{array}{l}\text { Symptomatic } \\
\qquad(n=20)\end{array}$ & \\
\hline A & $1(20)$ & $2(5)$ & $1(5)$ & $3(15)$ & $7(8)$ \\
\hline B1 & 0 & 0 & 0 & 0 & 0 \\
\hline B2 & $3(60)$ & $33(77)$ & $17(85)$ & $14(70)$ & $67(76)$ \\
\hline $\mathrm{D}$ & $1(20)$ & $8(19)$ & $2(10)$ & $3(15)$ & $14(16)$ \\
\hline
\end{tabular}

Table 5. Distribution of phylogenetic groups among E. coli from various sources

Data are shown as no. $(\%)$.

\begin{tabular}{|c|c|c|c|c|c|}
\hline \multirow[t]{2}{*}{ Phylogenetic group } & \multicolumn{2}{|c|}{ Present study } & \multicolumn{3}{|c|}{ Previous studies } \\
\hline & Vagina $(n=88)$ & Stool $(n=61)$ & Stool $*(n=168)$ & $\mathrm{CSF} \dagger(n=69)$ & $\operatorname{CSF} \ddagger(n=70)$ \\
\hline A & $7(8)$ & $17(28)$ & $67(40)$ & $4(6)$ & $1(1)$ \\
\hline B1 & 0 & 0 & $57(40)$ & 0 & $7(10)$ \\
\hline B2 & $67(76)$ & $27(44)$ & $19(11)$ & $47(68)$ & $57(81)$ \\
\hline $\mathrm{D}$ & $14(16)$ & $17(28)$ & $25(15)$ & $18(26)$ & $5(7)$ \\
\hline
\end{tabular}

* As detected by multiplex PCR (Duriez et al., 2001).

† As detected by RFLP (Bingen et al., 1998).

$\ddagger$ As detected by RAPD (Johnson et al., 2002).

Tsukamoto, 1997) and the prevalence of K1 among $E$. coli from any source (Table 3$)(P<0 \cdot 0001)$.

\section{Phylogenetic groups}

There were no significant differences in the distribution of phylogenetic groups between the VEC subsets (nonpregnant vs pregnant or asymptomatic vs symptomatic) (Table 4).

The prevalence of groups B2 and D in the VEC isolates $(92 \%)$ was significantly higher than that in the normal stool isolates from this study $(72 \%)$ (Table 5) $(P<0 \cdot 0005)$. The VEC isolates shared a very similar distribution of phylogenetic groups with the CSF isolates (Table 5) (Bingen et al., 1997; Johnson et al., 2002). The prevalence of groups B2 and D in the normal stool isolates from this study was far higher than that in the normal stool isolates from the previous study $(26 \%$; Table 5, $P<0 \cdot 0001$ ) (Duriez et al., 2001).

\section{Serotypes}

A supplementary table is available at http://mic. sgmjournals.org. See also Tsukamoto (1997). Among the VEC isolates, $71 \%(62 / 88)$ were typable for O antigen, whereas $25 \%(22 / 88)$ were $\mathrm{O}$ non-typable and
$5 \%(4 / 88)$ were $\mathrm{O}$ rough. The $62 \mathrm{O}$-typable VEC strains were found to be distributed into 20 serogroups or 31 different serotypes including HNT (H non-typable) and HNM (H non-motile). Identified in three or more VEC isolates were 8 common serotypes, including $\mathrm{O} 1: \mathrm{K} 1: \mathrm{H} 1$ $(n=5), \mathrm{O} 1: \mathrm{K} 1: \mathrm{H} 7(n=5), \mathrm{O} 2: \mathrm{K} 1: \mathrm{H} 7(n=6), \mathrm{O} 4: \mathrm{H} 5$ $(n=3), \mathrm{O} 6: \mathrm{H} 1(n=3), \mathrm{O} 18 \mathrm{ac}: \mathrm{K} 1: \mathrm{H} 7(n=4), \mathrm{O} 25: \mathrm{H} 1$ $(n=3)$ and O75:HNM $(n=6)$. These serotypes accounted for $56 \%(35 / 62)$ of serotypable isolates.

Among the 31 VEC serotypes, 10 serotypes $(\mathrm{O} 1: \mathrm{K} 1: \mathrm{H} 7$, $\mathrm{O} 2: \mathrm{K} 1: \mathrm{H} 7, \mathrm{O} 4: \mathrm{H} 5, \mathrm{O} 6: \mathrm{H} 1, \mathrm{O} 6: \mathrm{NM}, \mathrm{O} 16: \mathrm{K} 1: \mathrm{H} 6$, O16:K1:NM, O18ac:K1:H7, O75:HNM and O77:HNM) were also identified in the strains from urine and neonates. Seven ONT:K1:H4 strains were observed among the VEC isolates. All of them belonged to phylogenetic group B2 and had identical VF profiles; they all were positive for $i b e A, \mathrm{PAI}$ and fim $\mathrm{H}$, and negative for other VFs.

\section{DISCUSSION}

The relatively low presentation of $p a p C$, blyA and $c n f 1$ of VEC and UPEC strains in East Japan (Ibaraki prefecture) compared to that of UPEC strains in West Japan indicates the geographical distribution of VFs. Similarly, the lower presentation of $p a p C, b l y A$ and $c n f 1$ 
was also seen in the stool strains of East Japan $(18 \%$, $5 \%$ and $7 \%$ ) compared to that of West Japan $(28 \%$, $18 \%$ and $13 \%)$. The high occurrence of ibe A among VEC strains appears to reflect the population under scrutiny because the normal stool strains in this study also exhibited a higher prevalence of ibe $A(26 \%)$ than that in the other stool isolates (2\%) (Duriez et al., 2001). The increasing occurrence of $\mathrm{K} 1$ antigen among the E. coli from the stool, the vagina and the neonatal blood to neonatal CSF indicates a progressive accumulation of K1-positive E. coli strains along the faecalvaginal-neonatal course of infection. Since the K1 capsular antigen is known for serum resistance, antiphagocytosis and crossing the blood-brain barrier (Kim, 2001), the selection of faecal strains carrying such a pathogenic trait by the vaginal ecosystem could play an important role in extraintestinal pathogenesis.

Taken together, the VEC strains are very similar to other extraintestinal E. coli with respect to the overall distribution of VFs. With their common VF profiles, all extraintestinal E. coli can be considered 'virulent clones' (Finlay \& Falkow, 1997; Ochman et al., 2000). This in turn supports the concept of the recently proposed term, 'extraintestinal pathogenic E. coli' (ExPEC) (Russo \& Johnson, 2000).

Among four recognized phylogenetic groups (A, B1, B2 and D) (Herzer et al., 1990; Selander et al., 1996), the virulent extraintestinal E. coli strains belong mainly to group B2 and, to a lesser extent, to group D, whereas most commensal strains belong to group A (Bingen et al., 1998; Johnson \& Stell, 2000; Picard et al., 1999). The fact that most of the VEC strains $(92 \%)$ were grouped into $\mathrm{B} 2$ or D suggests that most of the VEC strains are potentially virulent. It should be noted, however, that this high occurrence of group B2 $(76 \%)$ in the VEC strains might have originated from the higher occurrence of group B2 (44\%) in the commensal faecal E. coli strains of Japanese populations. Duriez et al. (2001) has suggested that the commensal strains are phylogenetically distributed among geographically distinct human populations. This hypothesis could explain the difference between the distribution of phylogenetic groups of Japanese faecal strains (this study) and that of European and African faecal strains (Duriez et al., 2001). Therefore, it is worth examining more VEC isolates from distinct geographical populations to better understand the role of VEC in extraintestinal infections.

The serogroups O1, O2, O4, O6, O18, O25 and O75 found in three or more VEC strains have also been reported as the common serogroups in UPEC (Czirok et al., 1986; Korhonen et al., 1985; Mulder et al., 1984; Orskov et al., 1982; Sandberg et al., 1988; Stenqvist et al., 1987; Vaisanen-Rhen et al., 1984) and E. coli of neonatal meningitis or septicaemia (Cross et al., 1984; Korhonen et al., 1985; McCabe et al., 1978; McCracken et al., 1974; Robbins et al., 1974). Among 10 serotypes that were distributed elsewhere in the VEC and other extraintestinal strains of our study, O18ac: $\mathrm{K} 1: \mathrm{H} 7$ strains of cystitis, neonatal bacterial meningitis and faecal origin have already been shown to be clonally derived (Johnson et al., 2001). The strains belonging to the remaining nine serotypes could also be clonal, though further examination is needed for confirmation.

Inasmuch as $39 \%(12 / 31)$ of serotypes in the VEC strains were restricted to the vagina and the remaining $61 \%(19 / 31)$ can be found elsewhere, it is likely that a subset of the VEC, the former group, is confined locally as the vagina-specific residents whilst the latter group can spread to and exist in other extraintestinal sites.

In conclusion, our data demonstrate that the VEC share common VF profiles, phylogenetic groups and serotypes with E. coli strains from urinary and neonatal (blood and CSF) origins. This study provides additional evidence for a link among extraintestinal E. coli, which in turn supports the concept that VEC are a reservoir along the 'faecal-vaginal-urinary/neonatal' course of transmission in extraintestinal E. coli infections.

\section{ACKNOWLEDGEMENTS}

We thank Dr Kozo Fujita (Sapporo City Institute of Public Health, Japan), Dr Hiroyuki Kitajima (Osaka Medical Center and Research Institute for Maternal and Child Health, Japan), Dr Shingo Yamamoto (Department of Urology, Faculty of Medicine, Kyoto University, Japan) and Dr Shigemi Hitomi (Department of Infectious Diseases, Institute of Clinical Medicine, University of Tsukuba, Japan) for providing bacterial strains. This work was supported by Grant No. 12877045 from the Ministry of Education, Culture, Sports, Science and Technology of Japan.

\section{REFERENCES}

Bartlett, J. G., Onderdonk, A. B., Drude, E., Goldstein, C., Anderka, M., Alpert, S. \& McCormack, W. M. (1977). Quantitative bacteriology of the vaginal flora. J Infect Dis 136, 271-277.

Bingen, E., Bonacorsi, S., Brahimi, N., Denamur, E. \& Elion, J. (1997). Virulence patterns of Escherichia coli K1 strains associated with neonatal meningitis. J Clin Microbiol 35, 2981-2982.

Bingen, E., Picard, B., Brahimi, N., Mathy, S., Desjardins, P., Elion, J. \& Denamur, E. (1998). Phylogenetic analysis of Escherichia coli strains causing neonatal meningitis suggests horizontal gene transfer from a predominant pool of highly virulent B2 group strains. J Infect Dis 177, 642-650.

Chow, A. W., Percival-Smith, R., Bartlett, K. H., Goldring, A. M. \& Morrison, B. J. (1986). Vaginal colonization with Escherichia coli in healthy women. Determination of relative risks by quantitative culture and multivariate statistical analysis. Am J Obstet Gynecol 154, 120-126.

Clermont, O., Bonacorsi, S. \& Bingen, E. (2000). Rapid and simple determination of the Escherichia coli phylogenetic group. Appl Environ Microbiol 66, 4555-4558.

Cross, A., Orskov, I., Orskov, F., Sadoff, J. \& Gemski, P. (1984). Identification of Escherichia coli $\mathrm{K} 1$ antigen. J Clin Microbiol 20, 302-304.

Czirok, E., Milch, H., Csiszar, K. \& Csik, M. (1986). Virulence factors of Escherichia coli. III. Correlation with Escherichia coli pathogenicity of haemolysin production, haemagglutinating capacity, antigens $\mathrm{K} 1, \mathrm{~K} 5$, and colicinogenicity. Acta Microbiol Hung 33, 69-83. 
Duriez, P., Clermont, O., Bonacorsi, S., Bingen, E., Chaventre, A., Elion, J., Picard, B. \& Denamur, E. (2001). Commensal Escherichia coli isolates are phylogenetically distributed among geographically distinct human populations. Microbiology 147, 1671-1676.

Finlay, B. B. \& Falkow, S. (1997). Common themes in microbial pathogenicity revisited. Microbiol Mol Biol Rev 61, 136-169.

Gross, R. J., Cheasty, T. \& Rowe, B. (1977). Isolation of bacteriophages specific for the K1 polysaccharide antigen of Escherichia coli. J Clin Microbiol 6, 548-550.

Hebelka, M., Lincoln, K. \& Sandberg, T. (1993). Sexual acquisition of acute pyelonephritis in a man. Scand J Infect Dis 25, 141-143.

Heinonen, P. K. \& Miettinen, A. (1994). Laparoscopic study on the microbiology and severity of acute pelvic inflammatory disease. Eur J Obstet Gynecol Reprod Biol 57, 85-89.

Herzer, P. J., Inouye, S., Inouye, M. \& Whittam, T. S. (1990). Phylogenetic distribution of branched RNA-linked multicopy single-stranded DNA among natural isolates of Escherichia coli. J Bacteriol 172, 6175-6181.

Hillier, S. L., Krohn, M. A., Rabe, L. K., Klebanoff, S. J. \& Eschenbach, D. A. (1993). The normal vaginal flora, $\mathrm{H}_{2} \mathrm{O}_{2}{ }^{-}$ producing lactobacilli, and bacterial vaginosis in pregnant women. Clin Infect Dis 16 Suppl 4, S273-S281.

Huang, S. H., Wass, C., Fu, Q., Prasadarao, N. V., Stins, M. \& Kim, K. S. (1995). Escherichia coli invasion of brain microvascular endothelial cells in vitro and in vivo: molecular cloning and characterization of invasion gene ibe10. Infect Immun $\mathbf{6 3}$, 4470-4475.

Johnson, J. R. \& Brown, J. J. (1996). A novel multiply primed polymerase chain reaction assay for identification of variant papG genes encoding the Gal(alpha 1-4)Gal-binding PapG adhesins of Escherichia coli. J Infect Dis 173, 920-926.

Johnson, J. R. \& Stell, A. L. (2000). Extended virulence genotypes of Escherichia coli strains from patients with urosepsis in relation to phylogeny and host compromise. J Infect Dis 181, 261-272.

Johnson, J. R., Delavari, P. \& O’Bryan, T. T. (2001). Escherichia coli O18:K1:H7 Isolates from patients with acute cystitis and neonatal meningitis exhibit common phylogenetic origins and virulence factor profiles. J Infect Dis 183, 425-434.

Johnson, J. R., Oswald, E., O’Bryan, T. T., Kuskowski, M. A. \& Spanjaard, L. (2002). Phylogenetic distribution of virulenceassociated genes among Escherichia coli isolates associated with neonatal bacterial meningitis in the Netherlands. J Infect Dis 185, 774-784.

Kim, K. S. (2001). Escherichia coli translocation at the blood-brain barrier. Infect Immun 69, 5217-5222.

Korhonen, T. K., Valtonen, M. V., Parkkinen, J., Vaisanen-Rhen, V., Finne, J., Orskov, F., Orskov, I., Svenson, S. B. \& Makela, P. H. (1985). Serotypes, hemolysin production, and receptor recognition of Escherichia coli strains associated with neonatal sepsis and meningitis. Infect Immun 48, 486-491.

Krohn, M. A., Thwin, S. S., Rabe, L. K., Brown, Z. \& Hillier, S. L. (1997). Vaginal colonization by Escherichia coli as a risk factor for very low birth weight delivery and other perinatal complications. J Infect Dis 175, 606-610.

Larsen, B. \& Galask, R. P. (1980). Vaginal microbial flora: practical and theoretic relevance. Obstet Gynecol 55, 100S-113S.

Le Bouguenec, C., Archambaud, M. \& Labigne, A. (1992). Rapid and specific detection of the pap, $a f a$, and $s f a$ adhesin-encoding operons in uropathogenic Escherichia coli strains by polymerase chain reaction. J Clin Microbiol 30, 1189-1193.

McCabe, W. R., Kaijser, B., Olling, S., Uwaydah, M. \& Hanson, L. A. (1978). Escherichia coli in bacteremia: $\mathrm{K}$ and $\mathrm{O}$ antigens and serum sensitivity of strains from adults and neonates. J Infect Dis 138, 33-41.

McCracken, G. H., Jr, Sarff, L. D., Glode, M. P., Mize, S. G., Schiffer, M. S., Robbins, J. B., Gotschlich, E. C., Orskov, I. \& Orskov, F. (1974). Relation between Escherichia coli K1 capsular polysaccharide antigen and clinical outcome in neonatal meningitis. Lancet 2, 246-250.

Miyazaki, J., Ba-Thein, W., Kumao, T., Obata Yasuoka, M., Akaza, H. \& Hayashi, H. (2002). Type 1, P and S fimbriae, and afimbrial adhesin I are not essential for uropathogenic Escherichia coli to adhere to and invade bladder epithelial cells. FEMS Immunol Med Microbiol 33, 23-26.

Mulder, C. J., van Alphen, L. \& Zanen, H. C. (1984). Neonatal meningitis caused by Escherichia coli in The Netherlands. J Infect Dis 150, 935-940.

Ochman, H., Lawrence, J. G. \& Groisman, E. A. (2000). Lateral gene transfer and the nature of bacterial innovation. Nature 405, 299-304.

O'Grady, F. W., McHerry, M. A., Richards, B., Cattell, W. R. \& O'Farrell, S. M. (1970). Introital enterobacteria, urinary infection, and the urethral syndrome. Lancet 2, 1208-1210.

Orskov, F. \& Orskov, I. (1975). Escherichia coli O:H serotypes isolated from human blood. Prevalence of the K1 antigen with technical details of $\mathrm{O}$ and $\mathrm{H}$ antigenic determination. Acta Pathol Microbiol Scand Suppl 83, 595-600.

Orskov, I., Orskov, F., Birch-Andersen, A., Kanamori, M. \& Svanborg-Eden, C. (1982). O, K, H and fimbrial antigens in Escherichia coli serotypes associated with pyelonephritis and cystitis. Scand J Infect Dis Suppl 33, 18-25.

Picard, B., Garcia, J. S., Gouriou, S., Duriez, P., Brahimi, N., Bingen, E., Elion, J. \& Denamur, E. (1999). The link between phylogeny and virulence in Escherichia coli extraintestinal infection. Infect Immun 67, 546-553.

Robbins, J. B., McCracken, G. H., Gotschlich, E. C., Orskov, F., Orskov, I. \& Hanson, L. A. (1974). Escherichia coli K1 capsular polysaccharide associated with neonatal meningitis. $N$ Engl J Med 290, 1216-1220.

Russo, T. A. \& Johnson, J. R. (2000). Proposal for a new inclusive designation for extraintestinal pathogenic isolates of Escherichia coli: ExPEC. J Infect Dis 181, 1753-1754.

Sandberg, T., Kaijser, B., Lidin-Janson, G., Lincoln, K., Orskov, F., Orskov, I., Stokland, E. \& Svanborg-Eden, C. (1988). Virulence of Escherichia coli in relation to host factors in women with symptomatic urinary tract infection. J Clin Microbiol 26, 1471-1476.

Sarff, L. D., McCracken, G. H., Schiffer, M. S., Glode, M. P., Robbins, J. B., Orskov, I. \& Orskov, F. (1975). Epidemiology of Escherichia coli $\mathrm{K} 1$ in healthy and diseased newborns. Lancet 1, 1099-1104.

Schiffer, M. S., Oliveira, E., Glode, M. P., McCracken, G. H., Sarff, L. M. \& Robbins, J. B. (1976). A review: relation between invasiveness and the $\mathrm{K} 1$ capsular polysaccharide of Escherichia coli. Pediatr Res 10, 82-87.

Selander, R. K., Gaugant, D. A. \& Whittam, T. S. (1996). Genetic Structure and Variation in Natural Populations of Escherichia coli, 2nd edn. Washington, DC: American Society for Microbiology.

Siitonen, A. (1992). Escherichia coli in fecal flora of healthy adults: serotypes, $\mathrm{P}$ and type 1C fimbriae, non-P mannoseresistant adhesins, and hemolytic activity. J Infect Dis 166, 1058-1065.

Stamey, T. A. \& Sexton, C. C. (1975). The role of vaginal 
colonization with enterobacteriaceae in recurrent urinary infections. J Urol 113, 214-217.

Stenqvist, K., Sandberg, T., Lidin-Janson, G., Orskov, F., Orskov, I. \& Svanborg-Eden, C. (1987). Virulence factors of Escherichia coli in urinary isolates from pregnant women. J Infect Dis 156, 870-877.

Tashjian, J. H., Coulam, C. B. \& Washington, J. A. (1976). Vaginal flora in asymptomatic women. Mayo Clin Proc 51, 557-561.

Tsukamoto, T. (1997). PCR method for detection of K1 antigen and serotypes of Escherichia coli isolated from extraintestinal infection. Kansenshogaku Zasshi 71, 125-129.

Tsukamoto, T. \& Kanki, M. (1999). Detection of O157 and H7 antigen genes of Escherichia coli by PCR. Jpn J Food Microbiol 16, 197-200.
Vaisanen-Rhen, V., Elo, J., Vaisanen, E., Siitonen, A., Orskov, I., Orskov, F., Svenson, S. B., Makela, P. H. \& Korhonen, T. K. (1984). P-fimbriated clones among uropathogenic Escherichia coli strains. Infect Immun 43, 149-155.

Yamamoto, S., Terai, A., Yuri, K., Kurazono, H., Takeda, Y. \& Yoshida, O. (1995a). Detection of urovirulence factors in Escherichia coli by multiplex polymerase chain reaction. FEMS Immunol Med Microbiol 12, 85-90.

Yamamoto, S., Tsukamoto, T., Terai, A., Kurazono, H., Takeda, Y. \& Yoshida, O. (1995b). Distribution of virulence factors in Escherichia coli isolated from urine of cystitis patients. Microbiol Immunol 39, 401-404.

Received 20 March 2002; revised 29 May 2002; accepted 30 May 2002. 